The $7^{\text {th }}$ International Conference on Engineering Education for Sustainable Development \begin{tabular}{r|r} 
EESD'15 & The $7^{\text {h }}$ International Conference on Ener, Canada, June 9 to 12, 2015
\end{tabular}

\title{
SUSTAINABILITY IN BIOENERGY ACADEMY FOR TEACHERS (BEAT): CHANGING PERSPECTIVES AND PRACTICES TOWARD "GREENING" THE CURRICULA
}

\author{
Madhumi Mitra ${ }^{1,2}$, Abhijit Nagchaudhuri ${ }^{1}$, Courtney Shirvani ${ }^{1}$, and Xavier Henry ${ }^{1}$ \\ ${ }^{1}$ University of Maryland Eastern Shore, USA \\ 2 mmitra@umes.edu
}

\begin{abstract}
A holistic approach of sustainability grounded in environmental concerns, also incorporates the dimensions of culture, economy, and social justice. It can be an added attraction bringing together various disciplines to explore pathways through which sustainability can be addressed in a practical manner. A one-week summer institute on Bioenergy and Bioproducts for educators from middle and high schools, and university faculty across STEAM (Science, Technology, Engineering, Agriculture, and Mathematics) disciplines was hosted by the University of Maryland Eastern Shore (UMES). This program is geared towards helping reform educational infrastructure by promoting multidisciplinary activities and content in the areas of sustainability, bioenergy, and bioproducts. The objectives of the Bioenergy Academy are: 1) to provide a systems-perspective in sustainability, bioenergy, and bioproducts education to STEAM educators and researchers; and 2) to develop and provide curricular materials and a set of teaching tools to educators for enhancing instruction in the areas of sustainable bioenergy and bioproducts. The Academy focuses on lessons and activities pertaining to sustainability, systems thinking, renewable energy with particular emphasis on bioenergy, bioproducts, and environment and policies related to energy issues. The participants got the opportunity to acquire concrete experiences involving teamwork, time management, and project execution skills; reflected on their learning experiences through presentations at the end of the institute; developed concepts related to organic chemistry, physics, engineering design, instrumentation, mathematics, biological, and environmental sciences; and actively experimented with feedstocks to generate biodiesel and environmentally-friendly soaps using the glycerin produced from the biodiesel. The BITES ( Buildings, Industry, Transportation, Electricity, Scenarios) simulation tool developed by National Renewable Laboratory (NREL) of the United States Department of Energy (DOE) and made freely available over the internet allowed participants to play out scenarios to reduce carbon foot print based on those situations that can be realized through policy decisions leading to building improvements, reduction of industrial pollution, use of alternative fuels, electric cars, and other design modifications in the transportation sector, and cleaner and more efficient conversion technologies for electricity generation and conservation. A total of forty one educators have been trained through this program over a period of four years. The evaluation surveys (pre-and post) revealed that the educators gained substantial knowledge in the fields of sustainability, bioenergy, and bioproducts, and felt comfortable in implementing the content in their courses and laboratories.
\end{abstract}

\section{INTRODUCTION}

\subsection{Background Information}

The Planet Earth is facing several crises and with the unsustainable trends continuing, the world will witness increasing interconnected problems such as overpopulation, elevation of greenhouse gases leading to disruptive climate, poverty, resource depletion, loss of biodiversity, food and water scarcity, and political instability. These will eventually cause the life support systems enter a state of disequilibrium 
(Cortese 2012). Although being "green" or eco-conscious is a positive step towards a sustainable world, the term "sustainability" encompasses more than ecological integrity (Costanza et al. 1997).The three pillars or E's of sustainability (environment, economics, and equity) relate to fostering of communities that are healthy, safe, secure with economic opportunity for everyone while keeping the Earth's life support system viable (Elkington 2012). With the publication of Education for Sustainability: An Agenda for Action in 1996 by the United States President's Council on Sustainable Development, global sustainability has become prevalent in the curricula of K-16 classrooms. Sustainability does provide the context or foundation for education in many subject areas as it transcends disciplines. The concepts and activities on sustainability can also provide ample opportunities for educators to reinforce skills of critical thinking, systems thinking, collaboration, and communication.

The "green initiatives" of the University System of Maryland (USM) as a whole (http://www.usmd.edu/usm/sustainability/) have provided the foundation for the program, "BEAT (BioEnergy Academy for Teachers) the Energy Crisis and Enhance BLT (Bio-Energy Literacy for Teachers)" outlined in this paper. By providing educators with a comprehensive overview of the complexity of the "green" industries, more of today's students (tomorrow's workforce) are getting training to develop a systems perspective of the STEM (Science, Technology, Engineering, and Mathematics) fields. They are also learning to appreciate the wide range of skills necessary to address the challenges related to sustainability and climate change. Through directed training and programs such as the BEAT, the students reached so far have been developing a systems approach in problem solving, and increasing the likelihood of long-range improvements in the multitude of aspects encompassed in the "sustainability" issue. The primary goal of the BEAT program aligns with the overarching vision to expand the familiarity and knowledge of university faculty, in-service (middle, and high schools) as well as pre-service STEAM (science, technology, engineering, agriculture, and mathematics) teachers participating in the program with the complex topics of sustainable bio-energy and bio-products through a systems perspective. By training educators, it is anticipated that the students will become more aware of the greenhouse gas emissions, climate change, and the deleterious effects arising due to dependence on foreign oil. Exposing the middle and high school students, the university students, and the faculty to these topics will not only foster greater awareness, but also generate increased interest in STEAM careers. It probably does not come as a surprise that the recommendations made by the National Academy of Engineering for transforming engineering curricula for the new millennium echo that of the National Academy of Sciences and encourages sweeping changes that promote the integration of life-skills and civic responsibility outcomes along with academic outcomes as part of the overall educational experience of STEAM (Mitra et al 2013).

\subsection{Objectives}

The two objectives of the BEAT program are: a) To provide a systems-perspective in bio-energy/biofuel and sustainability issues to middle and high school in-service and pre-service teachers as well as university faculty. The overarching vision is to expand the familiarity and knowledge of middle school, and high school level STEAM teachers and undergraduate pre-service teachers as well as university faculty from agriculture, biology, chemistry, mathematics, engineering and technology participating in the program with the complex topics of sustainable bio-energy through a systems perspective. Bioenergy systems comprise biomass resources, supply systems, conversion technologies, and energy services (McCormick, 2010). Through the systems approach, the educators are exposing their students to the various perspectives related to the utilization of natural resources for bio-energy, ways to mitigate the global climate change, and understand the complexities that are involved in modern scientific and technological challenges. The students are also exposed to career choices in the cutting-edge STEAM disciplines; b)To develop and provide curricular materials and set of teaching tools for educators for enhancing instruction in the areas of sustainable bio-energy and sustainability in their classrooms--In addition to training the STEAM educators on a systems perspective of renewable energy, the program includes developing and providing curricular materials and laboratory tool kits for implementing classroom activities in bio-energy/bio-fuels and sustainability. The curricular materials are aligned with the national and state standards of science, technology, and mathematics and do provide sample lessons in bioenergy for middle, and high school students. 


\section{PROGRAM DESCRIPTION}

\subsection{Participant Selection}

The team (primary author and the coauthor) developed the program process and selection criteria. The educators submitted their resumes and a description of how they would use the training materials and/or training experience in their classrooms or research. Ten participants were selected during the first, second, and third years and eleven in the fourth year. The educators were a mix of in-service teachers, pre-service teachers, university faculty, teaching technicians, and graduate students. The high school teachers are represented cumulatively in the greatest number at $32 \%$, followed by middle school teachers and university faculty at $22 \%$. The graduate assistants represented $17 \%$ of the total participants across four years and the pre-service teachers made up $7 \%$ of the overall program participants (Table 1).

Table 1: Teaching Partner Professional Distribution

\begin{tabular}{lll}
\hline Teaching Partner Occupation & Total Number 2011-2014 & Total Number as Percentage \\
\hline Faculty & 9 & $22 \%$ \\
Research Assistants & 7 & $17 \%$ \\
High School Teachers & 13 & $32 \%$ \\
Middle School Teachers & 9 & $22 \%$ \\
Pre-service Teachers & 3 & $7 \%$ \\
\hline
\end{tabular}

\subsection{Activities at the Institute}

An important aspect of the BEAT program is to leverage the existing successful efforts (training programs, engagement exercises, and training Tools such as lab kits) to build a multidisciplinary, more comprehensive systems-oriented training package. Some of the highlights of the program activities during the one-week summer institute over the period of four years are delineated below:

\subsubsection{Biodiesel}

In the biodiesel activity, participants are introduced to the environmentally-friendly alternative to petrodiesel that is capable of being used in many of today's vehicles with diesel engines. The concepts of carbon neutrality are also expounded upon since it is an integral reason for the adoption of biodiesel as an alternative in today's carbon-heavy economies. Using products that are readily available from many "big-box" and automotive stores (HEET, a source of methanol and Drain opener, a source of sodium hydroxide), in addition to vegetable oils that were pressed from grains produced at the UMES research fields, small amounts of biodiesel were created in the lab to demonstrate the ease with which that fuel can be synthesized. The synthesis of the fuel also lead to discussions concerning the market penetration of the fuel in the US versus other global markets as well as the viability of the byproduct, glycerin, which was used in the glycerin soap making. This activity culminated in a brief tour of the university's biodiesel facilities where the fuel is regularly made from waste cooking oil for the use in farm equipment as well as for the diesel power generator powering the Integrated Multi-trophic Aquaculture (IMTA) facility where both shrimp and Gracilaria are produced in an attempt to address food, energy, and environment concerns in the future bioeconomy in a sustainable way (Figure 1).

\subsubsection{Gracilaria to Bioethanol}

Another biofuel to which participants were exposed was bioethanol. Here, macroalgae grown in the IMTA system is used to demonstrate the synthesis of ethanol which can be used as an additive to traditional gasoline or as its own alternative fuel in newer technology vehicles. The Gracilaria grown in the IMTA tank is commonly referred to as a nuisance alga since it readily forms pervasive blooms around the MidAtlantic region. Fortunately, from a biofuels perspective, the seaweed is comprised of quantities of easily fermented sugars, which is what the participants make use of in this lab, by simply macerating the alga and then treating it with basic baker's yeast and allowing the medium to culture over a 24- hour period. Thereafter, the medium can be filtered of solids and distilled to reveal the small amount of crude 
ethanol liberated by the process. In a retrospective discussion, participants were given the opportunity to again surmise as to the viability of such techniques and products in the current market place and to how the process may be improved to increase future viability (Figure 1).

\subsubsection{Algal PBR}

In this activity, participants were exposed to the concepts and of algal bioenergy and algal production systems. The scenario began with a brief lecture on algal ecology, to introduce micro and macro algae, eutrophication, algal storage compounds and other pertinent information. The activity then culminated in the participants constructing their own algal photobioreactors (PBR's) with Arthospira platensis inoculums and growth media using two $500 \mathrm{ml}$ plastic water bottles, aquarium air hoses, and an aquarium air-pump (Fig 2a). After constructing their PBR's, participants were also exposed to the implications of using PBR's in research. They also toured the facilities at the university where investigations using various scales of PBR's for the bioenergy and bioremediation efforts are undertaken.

\subsubsection{Glycerin Soap Synthesis}

In this activity, participants were introduced to a potentially valuable byproduct of biodiesel production using biodiesel glycerin (also known as glycerol). The glycerin that was previously obtained from the synthesis of biodiesel on campus was used to make environmentally-friendly soaps (Figure $2 b$ ). Kits, produced at the university contained all the necessary materials to allow for the saponification reaction to be satisfied safely. The basic reaction, an acid plus base, utilizes the fatty acids present in the triglycerides within the biodiesel glycerin and react with sodium hydroxide (Lye), to produce the soap (a salt) and glycerin, which serves as a moisturizer. Essential oils from a variety of sources were also added based upon the individual's preference to add another dimension of originality to the soap making process. After completing the reaction in the lab, the participants were exposed to several methods which they could employ to test the quality and safety of their soaps. Once the soaps were allowed to set and dry for 24 hours, the participants created their decorative bars as gifts and mementos.

\subsubsection{Sustainable Bioproducts}

Given the common misconceptions surrounding "green" and organic products, the bioproducts activity was designed to expose participants to the many facets of these up-and-coming products. Firstly, a discussion of what it means to be "green" and organic was held to arrive at a consensus. Several product demonstrations and trials were convened to put these products through their paces. Some of the activities included a tasting of algal food products such as seasoning and chips and the synthesis of a biopolymer packaging peanut to protect an egg during the egg drop activity. There was also a comparative assessment of various traditional versus green cleaning products against the common day-to-day stain causing compounds. The participants concluded that many of the green alternatives met or in some cases, exceeded their expectations in comparison with the performance of the traditional products.

\subsubsection{Mudwatt Microbial Fuel Cell}

The Mudwatt Microbial fuel cell (MFC) activity was centered on the potential for harnessing energy from living microorganisms. The MFC's is a bioelectrical device that takes advantage of the natural metabolic activities of microbes to produce electrical power directly from organic material. In this activity, the participants collected mud from the banks of a river located on the university's campus, and prepared it for the use in the MFC. The MFC chamber was then filled with the mud and allowed to sit until a steady pulse of light was emitted from the diode indicating peak productivity. The participants were also able to check the voltage obtained from their cells and compared it with different mud preparations (Figure 2c). The resistance of the MFC was also varied and its effect on the system was also recorded.

\subsubsection{Biolite}

Using the BioLite stove, the participants were exposed to the concept of thermodynamics, thermoelectric materials, the Seebeck effect, and the practical applications of their use in today's society. They also learned how the varied energy densities of feedstock may impact the energy production regime. The 
participants also collect various materials from outside and then tested their suitability for combustion within the stove. Thereafter, the stove was used to charge several mobile devices and also to roasting marshmallows and making green tea for the participants (Figure 2d).

\subsubsection{BITES}

Buildings, Industry, Transportation, and Electricity Scenarios (BITES) tool can be accessed from the URL:https://bites.nrel.gov/education.php. It has been developed by National Renewable Energy Laboratories (NREL) and allows users to create 'what if' scenarios to explore and compare outcomes related to baseline reference cases of the carbon footprint by adjusting energy inputs to buildings, industry, transportation, and electricity generation sectors in the United States. An activity developed in consultation with developers of the tool at NREL was integrated in the institute during the third year. The educators expressed that the tool allowed them to better comprehend the broader dimensions of the overall picture that provides relevance for the emphases on bioenergy and bioproducts during the institute. In particular, they could readily see the carbon implications of using more biofuels in the transportation sector, as well as increased use of biomass for heat and power generation for buildings, industries, and electricity generation sectors.

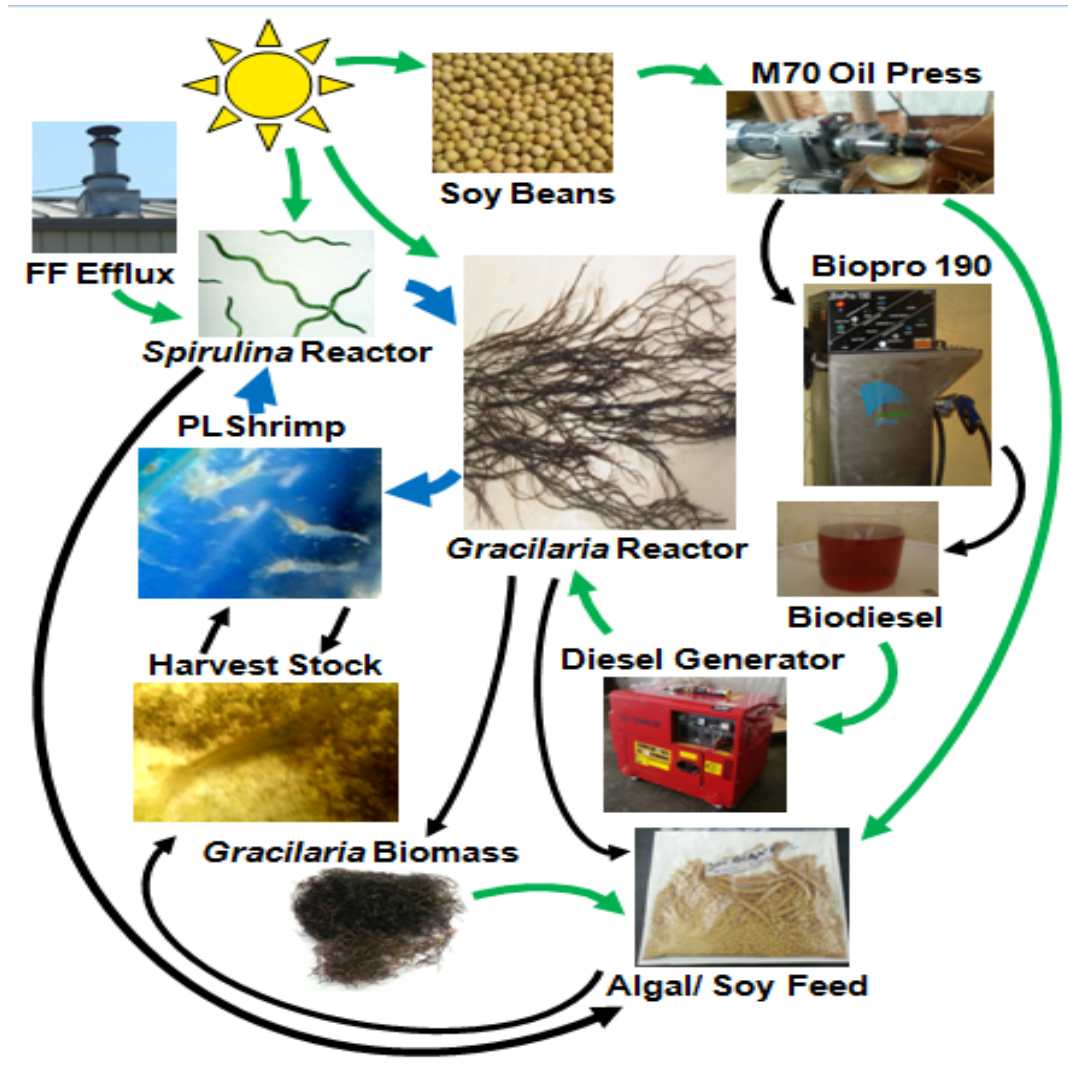

Figure 1: Schematic of IMTA System depicting the production of oil from oil seeds for biodiesel synthesis, the use of the biodiesel to meet the IMTA's electrical needs, and the production of Gracilaria biomass for bioethanol production. 


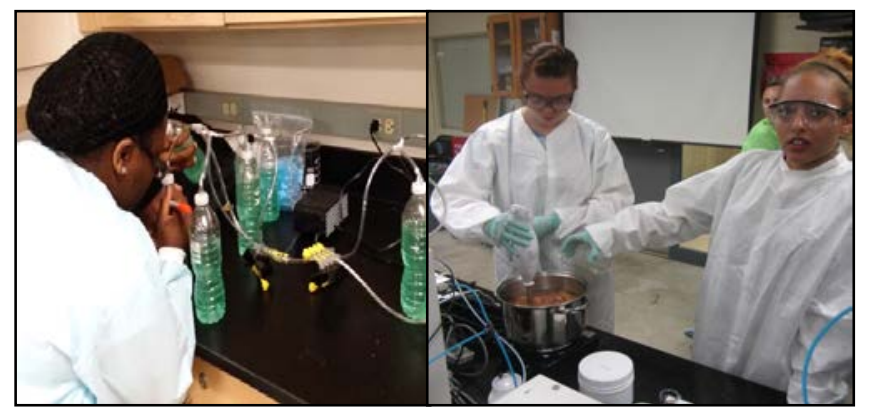

A

B

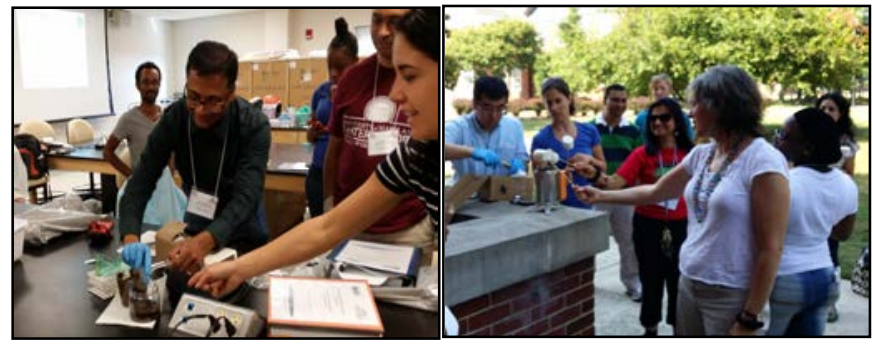

C

D

Figure 2: (A) Participants receiving a brief lecture on algae ecology and putting the final touches on their water bottle PBR systems; (B) Bioproduct soap making with biodiesel glycerin (C) Demonstration of the Mudwatt microbial fuel cell; (D) Participants using the Biolite to prepare roasted marshmallows and charge their cell phones.

\section{RESULTS: PROGRAM IMPACTS}

\subsection{Content Knowledge and Perception Surveys}

The educators were administered 20 multiple-choice pre-and post-surveys to measure their content knowledge in the areas of sustainability, renewable energy with a particular emphasis on bioenergy, and bioproducts before and after the institute. The pre-institute scores were much lower than the post-institute scores. The data indicated that there was an improvement in the scores of the post-tests for all the four years of the institute. Figure $3 \mathrm{~A}$ shows the average pre-test to post-test scores (in percentage) of the educators. The online perception survey was also a pre and post-assessment, in which the educators (participants teaching partners rated their comfort level of teaching the following topics within the following given areas: Agriculture, Sustainability, Forestry, Systems Thinking, Biomass, Biodiesel, Ethanol, BioHeat, BioPower, BioProducts, and Environmental Policy. The chart below shows the pre-test to posttest scores of 2011-2014 participants. The two different columns in the light blue and dark blue show the pre vs post-test percentages of educators who selected the criteria designations 'somewhat comfortable' or 'very comfortable' to describe their comfort-level with each of the listed topics. Comparing these two columns and the overall results of the PRE to POST perception surveys, there is an increase in perceived understanding of the participants with the outlined topics. This change is indicated by a shift toward increased levels of comfort through a self-assessed rating where each participant indicated his/her perceived comfort level with a given topic on a 5 point scale ranging from 'very uncomfortable',' somewhat uncomfortable', neutral ', to somewhat comfortable and very comfortable. Specifically, this change evidences a percentage shift and increase with respect to the above-neutral scale designations 'somewhat comfortable' and very comfortable'. Prior to the institute, an average of 25 percent of the participants selected the rating designations 'somewhat comfortable' and or 'very comfortable' in describing their level of comfort in teaching the given workshop topics: Environmental Policy, Bioproducts, Biopower, Bioheat, Ethanol, Biodiesel, Biomass, Systems Thinking, Sustainability, Agriculture and Forestry. However, at the conclusion of the institute almost $76 \%$ of the participants selected the higher 
comfort level ratings of 'somewhat comfortable' and or 'very comfortable' to describe their familiarity and competencies with these topics (Figure 3B).

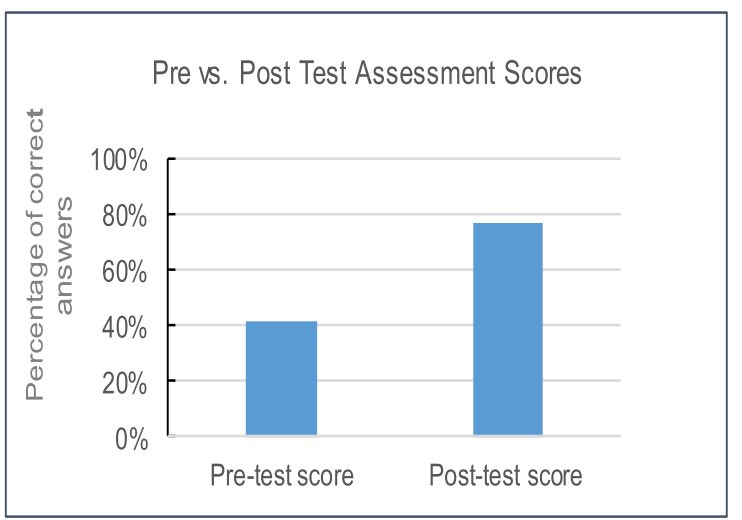

Figure 3A: Pre vs. Post Assessment Scores

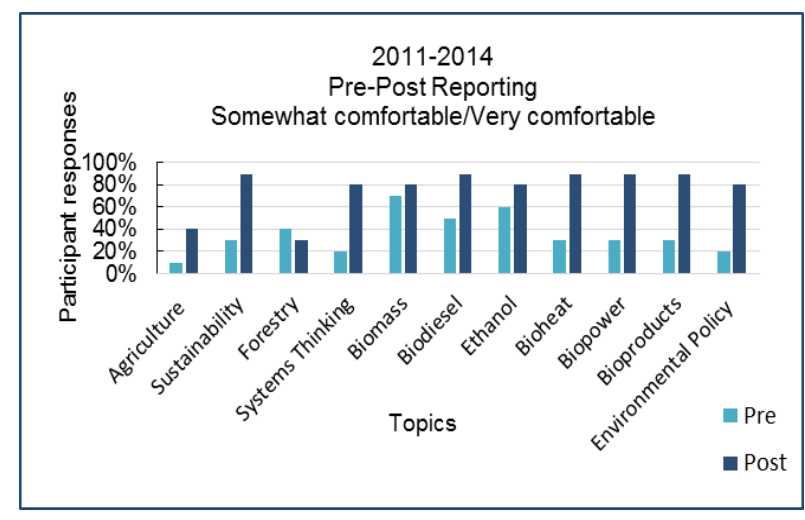

Figure 3B: Pre vs. Post Perception Survey

\subsection{BEAT Interdisciplinary Impacts}

Table 2 summarizes the activities which were implemented in various courses in middle and high schools as well as undergraduate education.

Table 2: Activities, disciplines, and level implemented and impacted

\begin{tabular}{|c|c|c|}
\hline Activity & Disciplines Impacted & Level \\
\hline Algal PBR & $\begin{array}{l}\text { Plant Science, Technology, Biology, Marine Botany, } \\
\text { Materials Science, AP Chemistry, General Integrated } \\
\text { Science }\end{array}$ & $\begin{array}{l}\text { Middle School, High School, Post- } \\
\text { Secondary }\end{array}$ \\
\hline Soap Lab & $\begin{array}{l}\text { Marine Botany, Biology and Earth Science, Biology and } \\
\text { Environmental Sciences, Chemistry, Transdisciplinary } \\
\text { Class, AP Chemistry, Materials Science }\end{array}$ & $\begin{array}{l}\text { Middle School, High School, Post- } \\
\text { Secondary }\end{array}$ \\
\hline VO to Biodiesel & $\begin{array}{l}\text { Biology, Chemistry, Technology, General and Analytical } \\
\text { Chemistry, General Integrated Science, Biology and } \\
\text { Environmental Sciences, AP Chemistry }\end{array}$ & $\begin{array}{l}\text { Middle School, High School, Post- } \\
\text { Secondary }\end{array}$ \\
\hline $\begin{array}{l}\text { Bioethanol lab from } \\
\text { feedstock and algae }\end{array}$ & $\begin{array}{l}\text { Ag. Science, Plant Science, Marine Botany, Chemistry, } \\
\text { Biology, and Environmental Sciences }\end{array}$ & High School, Post-Secondary \\
\hline $\begin{array}{l}\text { Sustainability activity- } \\
\text { design of homes, office }\end{array}$ & $\begin{array}{l}\text { General Integrated Sciences \& Human Ecology, } \\
\text { Transdisciplinary Class }\end{array}$ & Middle School, Post-Secondary \\
\hline Earth as an Apple & Earth Science \& Biology & High School \\
\hline $\begin{array}{l}\text { Sustainable } \\
\text { Bioproducts }\end{array}$ & $\begin{array}{l}\text { Chemistry, General Integrated Science, Materials Science, } \\
\text { Transdisciplinary Class }\end{array}$ & $\begin{array}{l}\text { Middle School, High School, Post- } \\
\text { Secondary }\end{array}$ \\
\hline BITES & $\begin{array}{l}\text { Pre-Algebra, Biology and Environmental Science, } \\
\text { Environmental Science, AP Chemistry }\end{array}$ & Middle School, High School, \\
\hline Biolite & Engineering, Transdisciplinary class & Post-Secondary \\
\hline Microbial Fuel Cell & Physics, Transdisciplinary class & Post-Secondary \\
\hline
\end{tabular}

\section{CONCLUSIONS AND DISCUSSION}

The program has been successful in engaging educators from the "STEAM" disciplines. Through handson learning activities in classrooms, fields, and laboratory settings, participants are more aware of the critically important issues of the "carbon cycle" and its relevance to renewable energy with a special focus on biomass, sustainability, climate change, and the utilization of natural resources and wastes for the generation of bio-products. Survey instruments for students' perception and appreciation of topics related to renewable energy and sustainability are currently being developed to document and analyze feedback 
from the high school and university students. Teacher training materials such as workbooks focusing on topics related to sustainability, bioenergy, and bio-products from natural resources and wastes have been developed along with assembled biodiesel, algal photobioreactor, and soap kits. As a follow-up, educators have been utilizing these resources to develop unit and lesson plans and to share with their peers so that more educators and their students are positively impacted. Besides contributing to the workforce development needs in areas of critical importance, the BEAT program efforts are enhancing awareness of sustainable practices such as reducing waste, promoting recycling, and advancing the green initiative on campus as well as on the lower Eastern Shore. Sustainable approaches to deal with issues related to energy, the environment, and agriculture are prominent in the grand challenges of the $21^{\text {st }}$ Century as identified by the National Academy of Science and the National Academy of Engineering (http://www.engineeringchallenges.org). The activities in the program are consistent with the recommendations of the National Academies with regard to transformational changes to agriculture, science, and engineering education for the new century and provide a foundation for continued education endeavors. Some of the activities (algae photobioreactor, biodiesel from cooking oil, environmentallyfriendly soap making, microbial fuel cell, Biolite, and BITES) from the institute are permanently incorporated in agriculture, food, and resource sciences; marine and environmental sciences; engineering curricula; and other STEAM courses at the University of Maryland Eastern Shore. There has been an increased interest in the students from sciences and engineering to participate in the experiential learning activities in the areas of renewable energy and sustainability. The BEAT program has facilitated in attracting students in pursuing STEAM degrees with a focus on sustainability issues. So far about 41 educators have been trained through the BEAT program and more than 20 undergraduate (about $60 \%$ from engineering) and graduate students have been involved with research-related activities in sustainability. The classroom tools, lab kits, and workbooks are self-sustaining for the educators not just in their classrooms but to other teachers through sharing of resources. The knowledge in the training sessions is transferable to other regions of the country.

\section{Acknowledgements}

The authors would like to acknowledge the generous support by the Unites States Department of Agriculture's Capacity Building grant \# 2012-02586 and Food Research Initiative (AFRI) Competitive Grant no. 2011-67009-30055 from the United States Department of Agriculture. Special thanks are extended to Dr. Kausik Das and Dr. Lei Zhang for developing and teaching the units on microbial fuel cell and Biolite respectively.

\section{References}

Cortese, A. "Foreward." In Holley Henderson, "Becoming a Green Professional: A Guide to Careers in Sustainable Architecture, Development and More. New York: John Wiley, 2012, xi-xiii.

Costanza, R, et al. 1997. The value of the world's ecosystem services and natural capital. Nature, 387 (5): 253-260.

Elkington, J. 2012. The Zeronauts: Breaking the Sustainability Barrier. New York: Routeledge.

McCormick, 2010. Communicating Bioenergy: a growing challenge, Biofuels, Bioproducts and Biorefining. 4 (5): 494-502.

Mitra, M, Nagchaudhuri, A, and Rutzke, C. 2013. Energizing the STEAM curricula with Bioenergy and Bioproducts. 2013 Proceedings of the American Association of Engineering Education, Atlanta, June 2013.

$21^{\text {st }}$ Century Grand Challenges of Engineering: http://www.engineeringchallenges.org/ 